\title{
LAS LIMITACIONES ADMINISTRATIVAS A LA PROPIEDAD POR RAZONES DE ORDENACIÓN TERRITORIAL Y ORDENACIÓN URBANÍSTICA EN VENEZUELA, Y EL CURIOSO CASO DE UNA LEY SANCIONADA QUE NUNCA ENTRÓ EN VIGENCIA
}

\author{
THE ADMINISTRATIVE CONSTRAINTS OF THE PROPERTY FOR REASONS OF \\ TERRITORIAL AND URBAN PLANNING IN VENEZUELA, AND THE A CURIOUS \\ CASE OF A LAW THAT SANCTIONED NEVER ENTERED IN VALIDITY
}

\author{
Allan Brewer-Carías \\ Universidad Central de Venezuela - Caracas - Venezuela
}

\begin{abstract}
RESUMO: O presente artigo trata das limitações administrativas da propriedade por razões de ordenamento territorial e urbanístico na Venezuela, trazendo um curioso caso de uma lei sancionada que nunca entrou em vigência. Primeiramente abordase o regime legal, destacando-se alguns aspectos da Lei Orgânica de 2005, a qual nunca entrou em vigência. Analisam-se os princípios constitucionais sobre a propriedade, sob a luz da Constituição de 1999. Através de uma pequena digressão histórica, são analisados os antecedentes constitucionais relacionados com a propriedade. Trata-se da garantia constitucional da propriedade e a reserva legal. $\mathrm{O}$ regime legislativo das limitações da propriedade é abordado, principalmente 0 regime da Lei Orgânica de Organização do Território de 1983 e os planos de ordenamento urbanístico. Sustentam-se alguns pontos sobre a urbanização e a edificação contidas na Lei Orgânica, bem como os projetos e a responsabilidade dos profissionais. Aborda-se sobre as consultas preliminares e outros procedimentos para se constituir uma edificação em uma zona de urbanização. Por fim alguns aspectos da limitação e uso da propriedade são tratados de acordo com a Lei Orgânica de 2005.
\end{abstract}

PALAVRAS CHAVE: Venezuela. Lei Orgânica. Limitações administrativas da propriedade. Constituição de 1999. Princípios Constitucionais. Planos de ordenamento urbanístico. Urbanização e edificação.

ABSTRACT: This article deals with the administrative constraints of the property for reasons of territorial and urban planning in Venezuela, bringing a curious case of a law that sanctioned never entered in validity. First it discusses the legal system, especially some aspects of the Organic Law of 2005, which never entered in validity. They're analyzed the principles constitutional on the property, under the light of the Constitution of 1999. Through a small historical tour, the constitutional antecedents related with the property are analyzed. It is treated of constitutional guarantee of property and the legal reserve. The regimen of legislative restrictions on the property is boarded, mainly the regimen of the Organic Law of Organization of the Territory of 1983 and the plans for urban planning. Some points are supported on the urbanization and the construction contained in the Organic Law, as well as the projects and the responsibility of professionals. It's approached on the preliminary 
consultations and other procedures to be a building in an area of urbanization. Finally some aspects of limitation and use of property are treated according to the Organic Law of 2005.

KEYWORDS: Venezuela. Organic law. Administrative limitations of the property. Constitution of 1999. Constitutional Principles. Plans of urban order. Urbanization and construction.

\section{INTRODUCCION}

El derecho de propiedad continúa siendo en el mundo contemporáneo, una de los pilares esenciales sobre las cuales está estructurado el Estado, siendo además uno de los condicionantes fundamentales de los regímenes políticos. Más propiedad privada y menos regulación por parte del Estado son el fundamento de los sistemas liberales; y, al contrario, más propiedad pública y mayor regulación pública de la propiedad privada está en la base de los sistemas socialistas, cada vez menos viables.

Pero independientemente de los regímenes políticos, lo cierto es que el régimen de la propiedad privada en el mundo contemporáneo es muy distinto al que se configuró durante el Siglo XIX, que la concebía como un derecho absoluto e inviolable. En la actualidad y desde comienzos del el Siglo pasado, la misma está sometida a múltiples limitaciones, restricciones, obligaciones y contribuciones impuestas por el interés general, al punto que su estudio se configura en una de las partes fundamentales del derecho administrativo contemporáneo. ${ }^{1}$

Nuestra intención, en estas notas, es referirnos a un aspecto específico del régimen de las limitaciones administrativas a la propiedad privada, particularmente en relación con la propiedad territorial o inmobiliaria, y es el derivado de la ordenación territorial y urbanística que durante las últimas décadas forma parte esencial de las políticas públicas. En Venezuela, en la actualidad, ese régimen está establecido en la Ley Orgánica para la Ordenación del Territorio de $1983^{2}$ y en la Ley Orgánica de Ordenación Urbanística de $1987^{3}$, las cuales pretendieron ser derogadas por la Ley Orgánica para la Planificación y Gestión de la Ordenación del

\footnotetext{
${ }^{1}$.Véase Allan R. Brewer-Carías, "El Derecho de Propiedad y la libertad Económica. Evolución y Situación actual" en Estudios sobre la Constitución, Libro Homenaje a Caldera. Tomo II, Caracas, 1979, p. 1.140 a 1.246 .

2 Publicada en Gaceta Oficial N ${ }^{\circ} 3.238$ de 11 de agosto de 1983. Véanse los comentarios a dicha Ley en Allan R. Brewer-Carías, "Introducción al régimen jurídico de la ordenación del territorio" en Ley Orgánica para la Ordenación del Territorio, Editorial Jurídica Venezolana, Caracas 1984.

${ }^{3}$ Publicada en Gaceta Oficial $N^{\circ} 33.868$ del 16 de diciembre de 1987. Véanse los comentarios a dicha Ley en Allan R. Brewer-Carías, "Introducción general al régimen legal de la ordenación urbanística" en Ley Orgánica de Ordenación Urbanística, Editorial Jurídica Venezolana, Caracas 1988.
} 
Territorio publicada el $1^{\circ}$ de septiembre de $2005^{4}$, la cual, sin embargo, y curiosamente, fue una Ley que nunca llegó a tener vigencia.

En efecto, al sancionarse esta última Ley Orgánica en septiembre de 2005, se dispuso una vacatio legis, indicando que entraría "en vigencia transcurrido seis meses a partir de su publicación en la Gaceta Oficial", es decir, el $1^{\circ}$ de marzo de 2006. Pero en esa misma fecha se publicó la Ley de Reforma Parcial de la Ley Orgánica para la Planificación y Gestión de la Ordenación del Territorio, ${ }^{5}$ con la cual se modificó la fecha de entrada en vigencia de la Ley Orgánica, disponiéndose otra vacatio legis de seis meses, con lo cual la Ley Orgánica debió haber entrado en vigencia el $1^{\circ}$ de septiembre de 2006. Sin embargo, de nuevo, en esa misma fecha, se publicó otra Ley de Reforma Parcial de la Ley Orgánica para la Planificación y Gestión de la Ordenación del Territorio, ${ }^{6}$ a los efectos de modificar, de nuevo, la fecha de entrada en vigencia de la Ley Orgánica, disponiéndose otra nueva vacatio legis, esta vez con indicación precisa de que la Ley Orgánica entraría "en vigencia el 28 de febrero de 2007."

Pero ello nunca ocurrió, pues la Ley Orgánica cuya entrada en vigencia fue tantas veces diferida, fue expresamente derogada por la "Ley Orgánica Derogatoria de la Ley Orgánica para la Planificación y Gestión de la Ordenación del Territorio", publicada el 27 de febrero de $2007,{ }^{7}$, en la cual simplemente se dispuso sin que nadie supiera cual había sido el motivo, que:

Artículo 1. Se deroga la Ley Orgánica para la Planificación y Gestión de la Ordenación del Territorio, sancionada el 15 de agosto de 2006 y publicada en la Gaceta Oficial de la República Bolivariana de Venezuela № 5.820 Extraordinario, de fecha 01 de septiembre de 2006.

Es decir, en septiembre de 2005, la Asamblea Nacional de Venezuela dictó una Ley Orgánica para que en definitiva nunca entrara en vigencia, lo que evidencia el deterioro de la calidad de la función legislativa en el país. Es decir, la Asamblea nacional en septiembre de 2005 dictó una Ley Orgánica destinada a derogar expresamente lo establecido en dos leyes orgánicas anteriores, de 1983 y de 1988, que habían tenido amplia aplicación, pero por disposición del mismo legislador, ello nunca ocurrió. Se trató de una forma curiosa de legislar para no legislar, o de legislar para que la ley sancionada nunca entrara en vigencia.

Los objetivos de esa Ley Orgánica que nunca estuvo vigente, en todo caso, eran establecer las disposiciones que debían regir el proceso general para la planificación y gestión de la ordenación del territorio, en concordancia con las realidades ecológicas y los principios, criterios, objetivos estratégicos del desarrollo sustentable, que incluyan la participación ciudadana y sirvan de base para la planificación del desarrollo endógeno, económico y social de la Nación (art. 1). Ello,

\footnotetext{
${ }^{4}$ Publicada en Gaceta Oficial No 38.263 de fecha 1 de septiembre de 2005, fue luego reimpresa por error material (omisión de los artículos 60 y 61) en la Gaceta Oficial № 38.264 del 2 de septiembre de 2005; y luego, de nuevo, en la Gaceta Oficial №38.279 del 23 de septiembre de 2005.

${ }^{5}$ Publicada en Gaceta Oficial № 38.388 de 1-3-2006

${ }^{6}$ Publicada en Gaceta Oficial № 38.513 de 1-9-2006, Nㅜ 5.820 Extraordinario de esa misma fecha.

${ }^{7}$ Publicada en Gaceta Oficial № 38.633 de 27-02-2007.
} 
sin embargo, sigue estando regulado en las mencionadas Ley Orgánica para la Ordenación del Territorio de 1983 y Ley Orgánica de Ordenación Urbanística de 1987.

Nos interesa, en estas notas, estudiar las líneas fundamentales de dicho régimen jurídico, para lo cual, antes nos referiremos a los principios constitucionales del régimen de la propiedad, que le sirve de fundamento a aquél, y al régimen de la propiedad territorial en las dos Leyes Orgánicas que se buscaba derogar. Comentaremos luego, las líneas generales del régimen de la propiedad en la Ley Orgánica sancionada que nunca entró en vigencia.

\section{LOS PRINCIPIOS CONSTITUCIONALES SOBRE LA PROPIEDAD}

\subsection{El régimen en la Constitución de 1999}

La Constitución de 1999, en relación con el derecho de propiedad, contiene una serie de normas fundamentales, entre las cuales se destacan las siguientes:

En primer lugar, el artículo 115, en el cual, en forma por demás escueta, se consagra y garantiza el derecho de propiedad y la posibilidad de su expropiación, en la forma siguiente:

Art. 115. Se garantiza el derecho de propiedad. Toda persona tiene derecho al uso, goce, disfrute y disposición de sus bienes. La propiedad estará sometida a las contribuciones, restricciones y obligaciones que establezca la ley con fines de utilidad pública o de interés general. Sólo por causa de utilidad pública o interés social, mediante sentencia firme y pago oportuno de justa indemnización, podrá ser declarada la expropiación de cualquier clase de bienes.

En segundo lugar, el artículo 116 que establece la prohibición a la confiscación en los términos siguientes:

Art. 116. No se decretarán ni ejecutarán confiscaciones de bienes sino
en los casos permitidos por esta Constitución. Por vía de excepción podrán
ser objeto de confiscación, mediante sentencia firme, los bienes de
personas naturales o jurídicas, nacionales o extranjeras, responsables de
delitos cometidos contra el patrimonio público, los bienes de quienes se
hayan enriquecido ilícitamente al amparo del Poder Público y los bienes
provenientes de las actividades comerciales, financieras o cualesquiera
otras vinculadas al tráfico ilícito de sustancias psicotrópicas y
estupefacientes.

Estas dos normas establecen los principios fundamentales de la propiedad en el mundo contemporáneo. Sin embargo, si se compara su contenido con el de las Constituciones anteriores, uno de los datos de mayor significación que resalta es la desaparición de la noción de "función social" de la propiedad que había sido el principio fundamental constitucional desde 1947. Por otra parte, se observa que se incorporaron al texto constitucional los atributos de la propiedad (uso, goce, disfrute y disposición) que en el ordenamiento jurídico venezolano histórico sólo estaban regulados en el Código Civil. Además, las normas reafirman la garantía de la reserva legal a la propiedad al disponerse que las contribuciones, restricciones y 
obligaciones que se establezcan con fines de utilidad pública o de interés general, deben necesariamente establecerse por ley.

En la Constitución de 1999, además se incorporaron otras normas en las cuales se trata el tema de la propiedad, que son las siguientes:

En tercer lugar, el artículo 55 en el cual se reguló el derecho ciudadano a la protección de su propiedad por parte del Estado:

Art. 55. Toda persona tiene derecho a la protección por parte del Estado, a través de los órganos de seguridad ciudadana regulados por ley, frente a situaciones que constituyan amenaza, vulnerabilidad o riesgo para la integridad física de las personas, sus propiedades, el disfrute de sus derechos y el cumplimiento de sus deberes.

En cuarto lugar, el artículo 98 que regula la propiedad intelectual:

Art. 98. La creación cultural es libre. Esta libertad comprende el derecho a la inversión, producción y divulgación de la obra creativa, científica, tecnológica y humanística, incluyendo la protección legal de los derechos del autor o de la autora sobre sus obras. El Estado reconocerá y protegerá la propiedad intelectual sobre las obras científicas, literarias y artísticas, invenciones, innovaciones, denominaciones, patentes, marcas y lemas de acuerdo con las condiciones y excepciones que establezcan la ley y los tratados internacionales suscritos y ratificados por la República en esta materia.

En quinto lugar, el artículo 307 que regula la propiedad rural y prohíbe el latifundio:

Artículo 307. El régimen latifundista es contrario al interés social. La ley dispondrá lo conducente en materia tributaria para gravar las tierras ociosas y establecerá las medidas necesarias para su transformación en unidades económicas productivas, rescatando igualmente las tierras de vocación agrícola. Los campesinos o campesinas y demás productores agropecuarios y productoras agropecuarias tienen derecho a la propiedad de la tierra, en los casos y formas especificados por la ley respectiva. El Estado protegerá y promoverá las formas asociativas y particulares de propiedad para garantizar la producción agrícola. El Estado velará por la ordenación sustentable de las tierras de vocación agrícola para asegurar su potencial agroalimentario.

En sexto lugar, el artículo 179 que regula el impuesto municipal a la propiedad territorial urbana y rural:

Artículo 179. Los Municipios tendrán los siguientes ingresos:

2. ... los impuestos sobre inmuebles urbanos; y la contribución especial sobre plusvalías de las propiedades generadas por cambios de uso o de intensidad de aprovechamiento con que se vean favorecidas por los planes de ordenación urbanística.

3. El impuesto territorial rural o sobre predios rurales, la participación en la contribución por mejoras y otros ramos tributarios nacionales 0 estadales, conforme a las leyes de creación de dichos tributos.

En octavo lugar, los artículos 119 y 124 que garantizan los derechos de propiedad colectiva de los pueblos indígenas:

Art. 119. El Estado reconocerá la existencia de los pueblos y comunidades indígenas, su organización social, política y económica, sus culturas, usos y costumbres, idiomas y religiones, así como su hábitat y derechos originarios sobre las tierras que ancestral y tradicionalmente 
ocupan y que son necesarias para desarrollar y garantizar sus formas de vida. Corresponderá al Ejecutivo Nacional, con la participación de los pueblos indígenas, demarcar y garantizar el derecho a la propiedad colectiva de sus tierras, las cuales serán inalienables, imprescriptibles, inembargables e intransferibles de acuerdo con lo establecido en esta Constitución y la ley.

Artículo 124. Se garantiza y protege la propiedad intelectual colectiva de los conocimientos, tecnologías e innovaciones de los pueblos indígenas. Toda actividad relacionada con los recursos genéticos y los conocimientos asociados a los mismos perseguirán beneficios colectivos. Se prohíbe el registro de patentes sobre estos recursos y conocimientos ancestrales.

Y por último, en noveno lugar, el artículo 308 que regula el régimen de propiedad colectiva:

Artículo 308. El Estado protegerá y promoverá la pequeña y mediana industria, las cooperativas, las cajas de ahorro, así como también la empresa familiar, la microempresa y cualquier otra forma de asociación comunitaria para el trabajo, el ahorro y el consumo, bajo régimen de propiedad colectiva, con el fin de fortalecer el desarrollo económico del país, sustentándolo en la iniciativa popular. Se asegurará la capacitación, la asistencia técnica y el financiamiento oportuno.

Todas estas normas de la Constitución de 1999 como la estructura general de la misma, puede decirse que tienen sus antecedentes inmediatos en la Constitución de 1947, y en todas las disposiciones constitucionales posteriores, incluyendo la de 1961.

\subsection{Antecedentes constitucionales inmediatos}

Todo el régimen constitucional contemporáneo en Venezuela incluyendo el relativo al derecho de propiedad se ha venido consolidando a partir de las regulaciones de la Constitución de 1947, en la cual se incorporó por primera vez el principio de la función social que la propiedad privada debe cumplir, y que, conduce a que por ello, la propiedad esté sometida a contribuciones, restricciones y obligaciones que establezca la ley por razones de utilidad pública e interés social. Esta previsión, que también recogió la Constitución de 1961, sin embargo, desapareció formalmente de la Constitución de 1999, aún cuando el sentido de la regulación en líneas generales conduce a ello.

En esta materia, puede decirse que la Constitución de 1947 fue bien exhaustiva al destinar a la propiedad los artículos 65 a 70 , en los que se dispuso lo siguiente:

Art. 65. La Nación garantiza el derecho de propiedad. En virtud de su función social, la propiedad estará sometida a las contribuciones, restricciones y obligaciones que establezca la ley con fines de utilidad pública o de interés general.

Todo autor o inventor tiene la propiedad exclusiva de su obra o invención y quien ideare una marca, el derecho de explotarla; todo ello conforme a las modalidades que establezcan las leyes y los tratados.

La ley podrá establecer prohibiciones -especiales para la adquisición, transferencia, uso y disfrute de determinadas clases de propiedad sea por su naturaleza, por su condición o por su situación en el territorio nacional. 
Art. 66. El Estado atenderá a la defensa y conservación de los recursos naturales del territorio venezolano y reglamentará el uso, goce y aprovechamiento de aquéllos, de acuerdo con los fines anteriormente citados.

Art. 67. En conformidad con la ley, sólo por causa de utilidad pública o de interés social, mediante sentencia firme y pago del precio, podrá ser declarada la expropiación de cualquier clase de bienes.

Cuando se trate de expropiación de tierras destinadas a la realización de la Reforma Agraria, y de la expropiación de inmuebles con fines de ensanche y acondicionamiento de las poblaciones, el pago podrá ser diferido por tiempo determinado, previo otorgamiento de garantía suficiente, en conformidad con lo que establezca la ley.

No se decretarán ni efectuarán confiscaciones de bienes en ningún caso, salvo lo previsto en el segundo aparte del Art. 21 de esta Constitución.

Art. 21. La confiscación únicamente podrá ser impuesta a los extranjeros y sólo en caso de conflicto con su país.

Art. 68. El derecho de propiedad privada territorial está condicionado por las disposiciones precedentes y por la obligación de mantener las tierras y bosques, que son su objeto, en producción socialmente útil. La ley determinará los efectos de esta disposición y las condiciones de su obligación.

Art. 69. El Estado realizará una acción planificada y sistemática, orientada a transformar la estructura agraria nacional.

Art. 70. Las tierras adquiridas por nacionales o extranjeros en territorio venezolano y destinadas a la explotación de concesiones mineras, comprendidas las de hidrocarburos y demás minerales combustibles, pasarán en plena propiedad al patrimonio de la Nación, sin indemnización alguna, al extinguirse por cualquier causa la respectiva concesión.

De estas normas de la Constitución de 1947, se deduce claramente que la propiedad ya había dejado de regularse como un derecho absoluto, y al contrario, se lo concebía como sometido a limitaciones, contribuciones, restricciones, obligaciones y prohibiciones que estableciera el legislador con fines de utilidad pública o de interés social.

Por otra parte, se destaca que en esa Constitución se estableció, por primera vez, el principio de la reversión respecto de las tierras destinadas a la explotación de concesiones mineras, comprendidas las de hidrocarburos y demás minerales combustibles, las cuales se disponía que debían pasar en plena propiedad al patrimonio de la Nación, sin indemnización alguna, al extinguirse la respectiva concesión. En esta forma, paralelamente a la expropiación —como forma de extinción de la propiedad privada mediando indemnización- se le dio cabida en el texto constitucional a otra forma de extinción de la propiedad, pero sin indemnización, como es la reversión.

La Constitución de 1953, aun cuando en forma más escueta, recogió los principios de la Constitución de 1947 en los siguientes términos:

Art. 35. Se garantiza a los habitantes de Venezuela...

9ํㅡㄹ El derecho de propiedad. En virtud de su función social la propiedad estará sometida a las contribuciones, restricciones y obligaciones que establezca la ley, de conformidad... con la cual también podrá ser declarada la expropiación de cualquier clase de bienes mediante sentencia firme y pago del precio.

La ley podrá establecer prohibiciones especiales para la adquisición, transferencia, uso y disfrute de determinadas clases de propiedad, por su №. 42 |p. 120 - 153| JAN - ABR 2014 
naturaleza, condición o situación en el territorio nacional. Las tierras adquiridas y destinadas a explotación de concesiones mineras, de hidrocarburos y demás minerales combustibles, pasarán en plena propiedad a la Nación, sin indemnización alguna, al extinguirse por cualquier causa la concesión respectiva.

Esta misma orientación se siguió en la Constitución de 1961, en la cual se incorporaron los siguientes principios en relación con la propiedad:

Art. 99. Se garantiza el derecho de propiedad. En virtud de su función social, la propiedad estará sometida a las contribuciones restricciones y obligaciones que establezca la ley con fines de utilidad pública o de interés social.

Art. 100. Los derechos sobre obras científicas, literarias y artísticas, invenciones, denominaciones, marcas y lemas, gozarán de protección por el tiempo y en las condiciones que la ley señale.

Art. 101. Sólo por causa de utilidad pública o de interés social, mediante sentencia firme y pago de indemnización, podrá ser declarada la expropiación de cualquier clase de bienes. En la expropiación de inmuebles con fines de reforma agraria 0 de ensanche 0 mejoramiento de poblaciones, y en los casos que por graves razones de interés nacional determine la ley, podrá establecerse el diferimiento del pago por tiempo determinado o su cancelación parcial mediante la emisión de bonos de aceptación obligatoria, con garantía suficiente.

Art. 102. No se decretarán ni ejecutarán confiscaciones sino en los casos permitidos por el Art. 250. Quedan a salvo, respecto de extranjeros, las medidas aceptadas por el derecho internacional.

Art. 103. Las tierras adquiridas con destino a la exploración o explosión de concesiones mineras, comprendidas las de hidrocarburos, y demás minerales combustibles, pasarán en plena propiedad a la Nación, sin indemnización alguna, al extinguirse por cualquier causa la concesión respectiva.

Art. 104. Los ferrocarriles, carreteras, oleoductos y otras vías de comunicaciones o de transporte construidos por empresas explotadoras de recursos naturales estarán al servicio del público, en las condiciones y con las limitaciones que establezca la ley.

Art. 105. El régimen latifundista es contrario al interés social. La ley dispondrá lo conducente a su eliminación, y establecerá normas encaminadas a dotar de tierra a los campesinos y trabajadores rurales que carezcan de ella, así como a proveerlos de los medios necesarios para hacerla producir.

Art. 106. El Estado atenderá a la defensa y conservación de los recursos naturales de su territorio, y la explotación de los mismos estará dirigida primordialmente al beneficio colectivo de los venezolanos.

Art. 133. Sólo el Estado puede poseer y usar anuas de guerra. Todas las que existan, se fabriquen o se introduzcan en el país pasarán a ser propiedad de la República, sin indemnización ni proceso. La fabricación, comercio, posesión y uso de otras armas serán reglamentadas por la ley.

De estos antecedentes constitucionales, como se señaló, se destaca el concepto constitucional de la función social a la propiedad, que tiene por objeto asegurar que "el derecho de propiedad no resulte incompatible con los intereses públicos" tal como lo precisó la antigua Corte Suprema de Justicia en una sentencia del 3 de diciembre de $1947^{8}$. En otra sentencia del 29 de mayo de 1972, la misma antigua Corte Suprema en Sala Político-Administrativa, precisó lo siguiente:

\footnotetext{
${ }^{8}$ Véase en Gaceta Oficial № 1.718, Extraordinaria, de 20-1-75, p. 21.
} №. 42 | p. 120 - 153| JAN - ABR 2014 
La función social que el constituyente atribuye a la propiedad en el Art. 99 de la Constitución, no es una cualidad inherente a las cosas que constituyen el objeto de ese derecho, sino un concepto jurídico de contenido económico y social, que deriva del cumplimiento de ciertas obligaciones o deberes que la ley impone al propietario, atendiendo a la naturaleza del bien de que se trate. ${ }^{9}$

Ahora bien, con base en este principio de la función social de la propiedad, el derecho de propiedad dejó definitivamente de tener el carácter absoluto, eterno, inmutable que pudo haber tenido durante el siglo XIX, y pasó a ser un derecho sometido a limitaciones de carácter legal.

\subsection{La garantía constitucional de la propiedad y la reserva legal}

En efecto, de las normas constitucionales antes referidas se deriva el principio fundamental de la garantía constitucional de la propiedad, que implica que las limitaciones, restricciones, obligaciones y contribuciones a la misma propiedad sólo pueden estar establecidas mediante leyes formales. Es, por tanto la ley, la que en definitiva fija el ámbito y régimen de la propiedad, tanto por razones de interés privado como de interés público. En el primer caso, se trata de las regulaciones a la propiedad con el objeto de establecer el régimen de la misma para regular las relaciones entre los diversos propietarios, es decir, de los propietarios entre sí; en el segundo caso, se trata de regulaciones al derecho de propiedad para armonizar su ejercicio con el interés público, disponiendo en este caso, las potestades de las autoridades ejecutivas o judiciales para adoptar medidas limitativas o restrictivas de la propiedad.

No es posible en este estudio que nos podamos referir ni siquiera someramente a todas las limitaciones al ejercicio del derecho de propiedad que han sido impuesta por razones de interés general, razón por la cual hemos limitado la aproximación al tema primero, refiriéndonos sólo a las limitaciones "administrativas" al derecho de propiedad solo respecto de la propiedad predial o territorial, y además, sólo a las establecidas legalmente para armonizar el uso, goce y disposición de la propiedad de la tierra a los dictados definidos por el legislador en materia de ordenación territorial y urbana.

Estas limitaciones circunscriben, delimitan o demarcan el uso de la propiedad territorial, precisándose sus límites, ámbito, alcance y duración. Tal como lo definió la antigua Corte Federal y de Casación en 1938, al referirse a las servidumbres de conductores eléctricos, indicando que las mismas:

Constituyen verdaderas limitaciones que afectan de modo general, el derecho de propiedad, limitaciones que el legislador impone en virtud de la potestad de que está investido y en atención a motivos de superior conveniencia o utilidad pública o social. Tales restricciones o limitaciones hacen parte integrante del régimen constitutivo del derecho mismo. ${ }^{10}$.

\footnotetext{
${ }^{9}$ Véase en Gaceta Oficial № 1.540, Extraordinaria, de 29-8-72, p. 35

${ }^{10}$ Véase Sentencia de 15 de febrero de 1958, en Memoria de 1939, p. 452.
} 
Pero además de configurar el entorno normal del derecho de propiedad, lo importante de las limitaciones administrativas a su ejercicio es que no lo extinguen ni anulan; al contrario, lo presuponen. Estas limitaciones, señaló la antigua Corte Federal y de Casación en Sala Federal en sentencia de 15 de diciembre de 1933, "disminuyen el derecho de dominio y señorío del legítimo dueño, no arruinan ni anulan este último derecho"11.

La consecuencia fundamental de las limitaciones "administrativas" al derecho de propiedad, es que configurando su entorno normal (derecho común), las mismas no inciden en la titularidad ni en la existencia del derecho, el cual se presupone; por lo que las limitaciones establecidas legalmente en principio no dan derecho a indemnización por parte del propietario limitado.

Históricamente estas limitaciones "administrativas" a la propiedad predial se comenzaron a establecer en los Códigos Civiles, en los cuales, como está indicado en el artículo 645 del Código Civil venezolano,

\begin{abstract}
"las limitaciones legales de la propiedad predial que tienen por objeto la utilidad pública, se refieren a la conservación de los bosques, al curso de las aguas, al paso por las orillas de los ríos y canales navegables, a la navegación aérea, a la construcción y reparación de los caminos y otras obras públicas. Todo cuanto concierne a estas limitaciones se determina por leyes y reglamentos especiales."
\end{abstract}

Estas limitaciones al ejercicio del derecho de propiedad predial, por otra parte, se pueden clasificar según el atributo de la propiedad en cuyo ejercicio incidan es decir, limitaciones al uso de la propiedad; limitaciones al goce ó disfrute de la propiedad; y limitaciones a la disposición de la propiedad.

\title{
1.4 Las limitaciones al uso de la propiedad por razones de ordenación territorial y urbana
}

Como hemos señalado, en este estudio sólo nos referiremos a una de las limitaciones al uso del derecho de propiedad territorial, la derivada de la ordenación territorial y urbana, teniendo en cuenta que entre las otras limitaciones de importancia están las motivadas, por ejemplo, por la proximidad al dominio público; por la conservación y racional aprovechamiento de los recursos naturales renovables; por la protección de los bienes culturales y por razones de seguridad y defensa.

El tema tiene particular interés particularmente en cuanto a la relación entre la propiedad privada del suelo y el urbanismo, pues éste en este campo, es el que define el marco del uso de la misma ${ }^{12}$. Como lo ha expresado la Corte Primera de lo Contencioso Administrativa en sentencia de 26 de julio de 2005:

\footnotetext{
${ }^{11}$ Véase en Memoria de 1934. pp. 240 y 241.

12 Véase en general Allan R. Brewer-Carias, Urbanismo y Propiedad Privada, Editorial Jurídica Venezolana, Caracas 1980; Allan R. Brewer-Carias, "Régimen urbanístico de la propiedad privada (Discurso de incorporación como individuo de numero de la Academia de Ciencias Políticas", en Boletín de la Academia de Ciencias Políticas y Sociales № 75-76, Año XXXVIII, Caracas Octubre
} 
El urbanismo es un mecanismo que permite la concreción de la función social de la propiedad. La ordenación urbanística constituye una limitación al derecho de propiedad, pues -tal y como señala la representación municipal- a través de éste se persigue obtener "un equilibrio entre el interés público y los intereses particulares de los propietarios", equilibrio que se verá manifestado mediante el valor que se efectúe del suelo urbano, a través de los diferentes tipos de planes.

Explica de ese modo la jurisprudencia extranjera al referirse a las regulaciones del derecho de propiedad que en este caso las "leyes de ordenación están muy lejos de establecer "solo medidas de policía concretas", respetando, como regulación ajena, "la imposición de obligaciones y limitación a los derechos" sino que, muy al contrario, establecen por sí mismas, o por remisión a los instrumentos normativos del planeamiento, los deberes y límites intrínsecos que configuran la función social de la propiedad del suelo, desde el punto de vista de la ordenación del territorio." (Sentencia del Tribunal Constitucional Español 37/1987). (Resaltado de esta Corte).

Se reconoce así entonces una íntima relación entre el derecho de propiedad y las regulaciones urbanísticas, llegándose a afirmar que "el reconocimiento de la propiedad urbanística no puede entenderse sin la sumisión del derecho al planeamiento urbanístico con todo lo que ello comporta en orden a la delimitación de su contenido; contenido normal de derecho de propiedad que, delimitado por el elemento institucional de la función social, viene dado por los deberes que son inherentes a esta forma de dominio y por los límites que forman parte de su contenido" (Fernández Caballal Almudena, El Urbanismo Finalista, Civitas, Madrid, 2002).

La ordenación urbanística como limitación al derecho de propiedad es, por naturaleza, de carácter general, pues su finalidad es el desarrollo armónico de la ciudad, y por ello es consustancial a esta materia la visión integral del espacio. $^{13}$

\section{EI REGIMEN legislativo DE LAS LIMITACIONES A LA PROPIEDAD POR RAZONES DE ORDENACIÓN TERRITORIAL Y URBANA}

\subsection{El régimen en la Ley Orgánica de Ordenación del Territorio de 1983}

\section{A) El régimen general como limitación legal a la propiedad}

Como se dijo, en 1983 se dictó en Venezuela la Ley Orgánica para la Ordenación del Territorio de $1983^{14}$, la cual estableció el régimen del suelo, derivado de la ordenación del territorio, configurándolo básicamente como una limitación legal a la propiedad en los términos establecidos tradicionalmente en el Código Civil y que fueron ampliados en la legislación especial.

1978 - Marzo 1979, p. 75-99; Tomás Polanco Alcántara, "Las limitaciones urbanística a la propiedad", en Revista de la Facultad de Derecho № 35, Caracas 1867, p. 31-47; Rafael Badell Madrid "Limitaciones legales al derecho de propiedad", en Temas de Derecho Administrativo. Libro Homenaje a Gonzalo Pérez Luciani, Volumen I. Tribunal Supremo de Justicia, Caracas, 2002, pp. 89-231.

${ }^{13}$ Caso Sindicato Agrícola, en Revista de Derecho Público, No. 103, Editorial Jurídica venezolana, Caracas 2005.Consultada en original

${ }^{14}$ Gaceta Oficial N ${ }^{\circ} 3.238$ de 11 de agosto de 1983. Véanse los comentarios a dicha Ley en Allan R. Brewer-Carías, "Introducción al régimen jurídico de la ordenación del territorio" en Ley Orgánica para la Ordenación del Territorio, Editorial Jurídica Venezolana, Caracas 1984. 
Por ello, la declaración del encabezamiento del artículo 63 de dicha Ley:

"Los usos regulados y permitidos en los Planes de Ordenación del Territorio, se consideran limitaciones legales a la propiedad y, en consecuencia no originan, por sí solos, derechos a indemnización".

Dicha norma precisó, además, complementando la noción de limitación legal a la propiedad, que solo podría ser reclamada una indemnización "en los casos de limitaciones que desnaturalicen las facultades del derecho de propiedad, siempre que produzcan un daño cierto, efectivo, individualizado, actual y cuantificable económicamente". En estos casos, a los efectos de determinar la indemnización, se debían seguir los criterios establecidos en la Ley de Expropiación por causa de Utilidad Pública o Social.

Por tanto, de acuerdo con esta norma, como principio, los usos regulados y permitidos en el Plan Nacional, en los Planes Regionales, en los Planes Sectoriales y en los Planes Estadales se configuraron como limitaciones legales a la propiedad, se insiste, en el sentido del Código Civil cuando regula las limitaciones legales a la propiedad predial que tienen por objeto la utilidad pública (Art. 645) y de algunas leyes especiales como la Ley Forestal, de Suelos y Aguas, respecto de los Parques Nacionales o las Zonas Protectoras, y la Ley Orgánica del Ambiente.

Sin embargo, en particular respecto de los planes de las Áreas bajo Régimen de Administración Especial, como serían los Parques Nacionales o las Zonas Protectoras, por ejemplo, la Ley Orgánica para la Ordenación del Territorio varió el sistema de limitación a la propiedad y prescribió expresamente en su artículo 64 que los planes de ordenamiento de

las áreas bajo régimen de administración especial solo surtirán efecto respecto de la propiedad cuando se publique en la Gaceta Oficial de la República el correspondiente Reglamento de uso.

En esta forma, contrariamente a lo que había sucedido con frecuencia con anterioridad, el solo hecho de que se declare un área como Parque Nacional o como Zona Protectora, no produce ningún efecto limitativo sobre la propiedad, siendo necesario que se regule el uso de las propiedades en el Reglamento respectivo, que debe dictarse conforme a lo previsto en el artículo 17, y sólo cuando éste se publique es que los usos previstos en los planes, surten efecto.

En esta forma, el legislador quiso poner término al abuso tradicional que había significado, por ejemplo, la declaratoria de Parques Nacionales o Zonas Protectoras, sin regulación de uso, con lo que se congelaba materialmente el uso de la propiedad en perjuicio de sus titulares. De acuerdo a la Ley Orgánica, en cambio, la limitación legal a la propiedad no surte efectos sin el Reglamento de Uso.

\section{B) La vinculación de la propiedad a los planes de ordenación urbanística}

En cuanto a la propiedad privada y a las limitaciones derivadas de los planes de ordenación urbanística, la Ley Orgánica precisó en su artículo 66 de la Ley que 
"los planes de ordenación urbanística delimitan el contenido del derecho de propiedad, quedando éste vinculado al destino fijado por los mismos".

Por tanto, no se trataba aquí de un derecho cuyo contenido se limita por un plan; sino de un derecho cuyo contenido lo establece el plan, quedando el derecho vinculado al destino fijado por los planes. Por ello la Ley Orgánica de 1983 considera nulas las autorizaciones de uso de la propiedad urbana contrarias a los planes.

Como lo ha argumentado la Corte primera de lo Contencioso Administrativo:

Ciertamente, la planificación urbanística delimita el contenido del derecho de propiedad al vincularlo al destino fijado en los planes (artículo 53 de la Ley Orgánica de Ordenación Urbanística), y esta delimitación está reservada, como restricción que es, a la norma. Se trata de establecer una ordenación del crecimiento y desarrollo urbano. Como indica Fiorini, estas restricciones tienen por esencia la generalidad; "la zonificación establece distintas cargas y prohibiciones para cada sector zonal." (Fiorini, Bartolomé. Derecho Administrativo, Tomo II, Edit. Abeledo Perrot, Buenos Aires, pág $126,1997)$. Es así inconcebible que la zonificación se entienda como una afectación concreta y específica a un uso exclusivo.

El carácter general e integral de la planificación urbana es cuestión no debatida, pues atañe a la naturaleza de la actividad planificadora y a la esencia de la actividad limitativa de derechos fundamentales. Así la doctrina precisa que el urbanismo tiene un carácter integral, pues "No debe olvidarse que el urbanismo tiene por objeto la ordenación del territorio en su totalidad, incidiendo de este modo sobre el conjunto de las actividades sociales y económicas que operan en el mismo." (Pérez Fernández, José Manuel. "La Ordenación espacial del equipamiento comercial: la planificación comercial. Planificación urbanística", en: El Derecho Administrativo en el umbral del siglo XXI. Homenaje al Profesor Dr. D. Ramón Martín Mateo, Tomo II, Edit. Tirant lo blanch, Valencia, 2000, p. 2717).

De igual manera afirma el autor español Estévez Goytre -al analizar la naturaleza jurídica de los Planes Urbanísticos- que se trata de un "conjunto de normas limitadoras de derechos y deberes de los propietarios de los predios" que son "de carácter general y obligatorio" (Estévez Goytre, Ricardo. "El Urbanismo y la Jurisdicción Contencioso-Administrativa. Estudio Jurisprudencial", en Revista Española de Derecho Urbanístico y Medio Ambiente, Marzo 2004). ${ }^{15}$

La vinculación de la propiedad al destino fijado por los planes, exige, por supuesto, que éstos existan. Por ello la afirmación categórica del artículo 66:

Las actuaciones que se realicen en el suelo con fines urbanísticos, requieren la previa aprobación del respectivo plan de ordenación urbanística, a los fines de la asignación de uso y su régimen correspondiente, así como de la fijación de volúmenes, densidades y demás procedimientos técnicos, sin que puedan otorgarse autorizaciones de uso del suelo en ausencia de planes.

Los criterios para la elaboración de los planes están establecidos en la Ley Orgánica (art. 19) así como la precisión de las funciones derivadas de las competencias urbanísticas relativas al régimen del suelo que tienen las autoridades (art. 67).

${ }^{15}$ Sentencia de 27-07-2005. Caso Sindicato Agrícola, en Revista de Derecho Público, No. 103, Editorial Jurídica Venezolana, Caracas 2005. 


\section{C) Los medios de control: las aprobaciones y autorizaciones administrativas}

La Ley Orgánica estableció un completo sistema de medios jurídicos para hacer efectivo el control de la ejecución de los planes, según que las actividades a controlar sean desarrolladas por los organismos del sector público o por los particulares. Se distinguieron así, las aprobaciones de las autorizaciones administrativas.

\section{a. Las aprobaciones administrativas}

La Ley Orgánica, en efecto, teniendo en cuenta que básicamente son las actividades del sector público las que más han contribuido a la desordenada ocupación del territorio, estableció como principio general que aquellas requieran, previa a su realización, un acto administrativo de aprobación por parte del organismo encargado del control de la ejecución de los planes.

En esa forma, se estableció el siguiente sistema:

1. Las decisiones que adopten los organismos de la Administración Pública Nacional, Central o Descentralizada que tengan incidencia espacial e impliquen acciones de ocupación del territorio de la importancia nacional y que se determinen reglamentariamente, deben ser aprobados por el Ministerio del Ambiente y de los Recursos Naturales Renovables, a los efectos de su conformidad con los lineamientos y previsiones del Plan Nacional de Ordenación del Territorio. A los efectos de precisar el alcance de esta exigencia, el artículo 49 de la Ley Orgánica prescribe que la aprobación administrativa se debe requerir en los procesos de toma de decisiones sobre localización y traslado de industrias; afectación de zonas para la reforma agraria; localización de grandes aprovechamientos de recursos naturales; localización de nuevas ciudades; trazado de los grandes corredores de vías de comunicación; y localización de puertos y aeropuertos.

2. Las decisiones que adopten los organismos de la Administración Pública Nacional, Central o Descentralizada o las que podían adoptar las antiguas Corporaciones de Desarrollo Regional que tengan incidencia espacial e implicasen acciones de ocupación del territorio de la importancia regional que se determinen reglamentariamente, deben ser aprobadas por los Gobernadores de las entidades federales, a los efectos de su conformidad con los lineamientos y previsiones de los Planes Regionales de Ordenación del Territorio. Conforme al artículo 50 de la Ley, los Gobernadores de las entidades federales, a los efectos de estas aprobaciones, deben estar asistidos por las unidades desconcentradas del Ministerio del Ambiente y de los Recursos Naturales Renovables que se determinen reglamentariamente. 
3. Las decisiones que adopten los organismos de la Administración Pública Nacional, Central o Descentralizada o las que adopten las autoridades regionales y estadales, que tengan incidencia espacial e impliquen acciones de ocupación del territorio en las áreas urbanas de la importancia que se determine reglamentariamente, deben ser aprobadas por los Municipios, a los efectos de su conformidad con los lineamientos y previsiones de los Planes de Ordenación Urbanística. Los Municipios, conforme al artículo 51 de la Ley, a los efectos de estas aprobaciones, pueden contar con la asistencia de las unidades desconcentradas del Ministerio con competencia en materia de Desarrollo Urbano.

Ahora bien, a los efectos de evitar la parálisis o retraso de las acciones administrativas, debido a la demora que pueda haber en el dictado de estas aprobaciones, la Ley, expresamente, en los artículos 49,50 y 51, previó la figura del silencio administrativo positivo, en el sentido de que: primero, obliga a que las aprobaciones se otorguen o se nieguen en un lapso de 60 días continuos; y segundo, prescribe que vencido dicho lapso sin que hubiese habido pronunciamiento expreso, la decisión se debe considerar aprobada.

Debe mencionarse, por último, que el artículo 70 de la Ley Orgánica estableció la sanción de nulidad respecto de los actos administrativos contrarios a las aprobaciones administrativas otorgadas conforme a la Ley, no pudiendo estas generar derechos a favor de sus destinatarios.

\section{b. Las autorizaciones administrativas}

En cuanto a las actividades de los particulares y entidades privadas que impliquen ocupación del territorio, prescribe el artículo 53 de la Ley Orgánica, que deben ser autorizadas previamente por las autoridades encargadas del control de la ejecución de los planes conforme a lo previsto en los mencionados artículos 43 a 48 (Capítulo II del Título IV), a los efectos de su conformidad con dichos planes, y dentro de sus respectivas competencias.

En todo caso, la Ley remite, a los reglamentos, la determinación de las actividades que requieren de autorización nacional del Ministerio del Ambiente a los efectos de su conformidad con el Plan Nacional, así como aquellas que sólo requieren autorización regional de los respectivos Gobernadores de las Entidades Federales, a los efectos de su conformidad con los Planes Regionales (art. 53). Por supuesto, en los casos en los cuales se otorgue la autorización nacional correspondiente, no se debe exigir la autorización regional.

A los efectos del otorgamiento de estas autorizaciones, y con el objeto de evitar paralizaciones y dilaciones en los trámites que deben realizar los particulares, la Ley también prevé la figura del silencio administrativo positivo, a cuyo efecto, el artículo 54 establece que el otorgamiento de las autorizaciones nacionales 0 regionales respectivas, debe decidirse en un lapso de 60 días continuos, a contar del recibo de la solicitud respectiva. Vencido dicho lapso, sin que se haya otorgado 
o negado la autorización, se debe considerar concedida, a cuyo efecto las autoridades respectivas están obligadas a otorgar la respectiva constancia.

Debe destacarse que se trata de una obligación legal ineludible, cuyo incumplimiento, por supuesto, compromete la responsabilidad del funcionario respectivo; y cuya exigencia puede hacerse efectiva, incluso, en vía contenciosoadministrativa contra la negativa o abstención.

En el caso de actividades a desarrollarse por particulares o entidades privadas en las áreas urbanas y que impliquen ocupación del territorio, el artículo 55 de la Ley Orgánica había exigido, que fueran autorizadas por los Municipios, mediante los correspondientes permisos de urbanización, construcción o de uso que estableciera la ley nacional respectiva o las Ordenanzas Municipales, todo lo cual se reguló posteriormente en la Ley Orgánica de Ordenación Urbanística de 1987. La Ley Orgánica para la Ordenación del Territorio, sin embargo, apuntaba a la simplificación procedimiental, indicando que:

\begin{abstract}
el procedimiento para la tramitación de las solicitudes de dichos permisos municipales deberá ser simplificado, y los mismos deben decidirse en un lapso de 60 días continuos, contados a partir del recibo de las solicitudes respectivas, vencido el cual, sin que se hubieran otorgado o negado los permisos, se considerarán concedidos, a cuyo efecto los Municipios están obligados a otorgar la respectiva constancia del permiso.
\end{abstract}

En todo caso, la Ley Orgánica aclaró expresamente que "serán nulas y sin ningún efecto, las autorizaciones otorgadas en contravención a los planes de ordenación del territorio" (art. 56).

A los efectos de regularizar las tramitaciones, la Ley Orgánica prescribía, en la última parte del artículo 55, que "las autoridades municipales conforme a las normas y procedimientos técnicos que establezca el Ministerio de Desarrollo Urbano, deberán dictar las Ordenanzas respectivas a los efectos de garantizar la celeridad de los procedimientos y los derechos de los interesados".

Por último debe señalarse que la autorización administrativa no sólo es el requisito indispensable para que los particulares puedan realizar actividades que impliquen ocupación del territorio, sino que es indispensable a los efectos del goce de beneficios e incentivos por parte de organismos públicos, así como para la obtención de créditos y financiamientos de parte de organismos públicos e instituciones de crédito particulares (art. 57).

\title{
2.2 El régimen en la Ley Orgánica de Ordenación Urbanística de 1987
}

\section{A) Las limitaciones a la propiedad privada}

Como se dijo, luego de las regulaciones de la ley Orgánica para la Ordenación del Territorio, la Ley Orgánica de Ordenación Urbanística fue dictada en 
1987, entró en vigencia en $1988,{ }^{16}$ y siguiendo la misma orientación establecida en el artículo 66 de aquella Ley Orgánica, dispuso en su artículo 52 que "la propiedad urbana tiene una función social", conforme lo prescribía el artículo 99 de la Constitución de 1961, la cual disponía que la propiedad "estará sometida a las contribuciones, restricciones y obligaciones que establezca la ley con fines de utilidad pública o de interés social".

Sin embargo, el artículo 52 de la Ley Orgánica de Ordenación Urbanística agregó que en virtud de la función social de la propiedad urbana, ella "estará sometida a las contribuciones, restricciones y obligaciones establecidas en esta Ley y en cualesquiera otras que se refieran a la materia urbanística, y en los reglamentos, planes y normas complementarias que dicten las autoridades urbanísticas competentes". Esta disposición, evidentemente era inconstitucional, pues se apartaba de lo establecido tanto en el artículo 99 como en el artículo 224 del Texto Fundamental de 1961, al prescribir que pudiera la propiedad privada estar sometida a "contribuciones, restricciones y obligaciones" establecidas "en reglamentos, planes y normas complementarias" que dicten las autoridades administrativas urbanísticas competentes, por ejemplo, un Ministerio o la autoridad municipal. Ello era y es evidentemente inconstitucional, pues sólo las leyes formales nacionales o locales pueden establecer contribuciones, restricciones y obligaciones a la propiedad en los respectivos campos de competencia nacional o municipal.

Por tanto, ningún "reglamento" o "norma complementaria" puede establecer dichas obligaciones, contribuciones o restricciones a la propiedad, y en cuanto a los "planes", sólo los planes de desarrollo urbano local, aprobados por Ordenanza, pueden establecerlas. Por tanto, los planes de ordenación urbanística que sólo son aprobados por Resolución Ministerial, no pueden en forma alguna, establecer restricciones, contribuciones $u$ obligaciones a la propiedad.

\section{B) La vinculación de la propiedad al plan}

Siguiendo también la orientación del artículo 66 de la Ley Orgánica de Ordenación del Territorio, el artículo 53 de la Ley Orgánica de Ordenación Urbanística estableció que:

Los planes de ordenación urbanística y de desarrollo urbano local delimitan el contenido del derecho de propiedad, quedando éste vinculado al destino fijado por dichos planes

Agregó además esta norma que:

Las contribuciones, restricciones y obligaciones establecidas por leyes, reglamentos, planes y ordenanzas urbanísticas se consideran limitaciones legales al derecho de propiedad, y en consecuencia no dan, por sí solas,

16 Publicada en Gaceta Oficial № 33.868 del 16 de diciembre de 1987. Véanse los comentarios a dicha Ley en Allan R. Brewer-Carías, "Introducción general al régimen legal de la ordenación urbanística" en Ley Orgánica de Ordenación Urbanística, Editorial Jurídica Venezolana, Caracas 1988. 
derecho a indemnización. Esta sólo podrá ser acordada en los casos de limitaciones que desnaturalicen el derecho de propiedad y produzcan un daño directo, cierto, actual, individualizado, y cuantificable económicamente. En estos casos, a los efectos de determinar la indemnización, se seguirán los criterios establecidos en la presente ley y en la Ley de Expropiación por causa de Utilidad Pública o Social.

Dejando aparte lo ya indicado sobre la inconstitucionalidad de la previsión del último aparte mencionado del artículo 53, en el sentido de que no pueden establecerse restricciones, contribuciones u obligaciones a la propiedad por vía de reglamento o de plan aprobado mediante Resolución, debe insistirse en la noción de "vinculatoriedad" al plan, como elemento central de delimitación del contenido del derecho o de propiedad ${ }^{17}$.

Por supuesto, de nuevo aquí, conforme a la garantía constitucional de la propiedad, el plan que puede delimitar en concreto el contenido de la propiedad, es el plan aprobado por ley formal, que en materia urbanística, es el plan de desarrollo urbano local aprobado por Ordenanza ${ }^{18}$. Por tanto, los otros planes de ordenación urbanística no pueden delimitar en forma alguna, en concreto, propiedades privadas, como en forma evidentemente inconstitucional lo establece el artículo 54 de la Ley Orgánica.

Bajo esta perspectiva, el segundo aparte del artículo 54 de la Ley Orgánica debe interpretarse como asignación de competencias, pero dentro de la limitación mencionada respecto de la afectación, en concreto, de la propiedad privada.

En efecto, el artículo 54 de la Ley Orgánica establece que:

\begin{abstract}
El Ministerio del Desarrollo Urbano y los Concejos Municipales, respectivamente, determinarán mediante la normativa aplicable y referida a los planes para los cuales tienen competencia atribuida, las distintas calificaciones del suelo urbano, y las condiciones y características de los procesos de urbanización, parcelamiento y reparcelamiento, con especial referencia a los asentamientos no controlados. En este último caso, las determinaciones que se establezcan deberán precisar las condiciones de dichos asentamientos a los fines de señalar las características de desarrollo aplicables, y las etapas y modalidades del proceso de erradicación, si tal fuera el caso.
\end{abstract}

Por supuesto, la "calificación del suelo urbano" que pueda establecerse en los planes nacionales de ordenación urbanística, sólo puede ser de orden general ("normas") para su desarrollo concreto por los planes de desarrollo urbano local, y no pueden afectar directamente propiedades privadas. En este sentido es que debe interpretarse la expresión "determinar los usos del suelo urbano" (art. 17, ord. 49) y la "definición del uso del suelo" (art. 24, ord. 39) utilizada al describirse los objetivos y contenidos de dichos planes nacionales.

Al contrario, la calificación del suelo urbano que puede afectar directamente la propiedad privada, es la establecida en los planes de desarrollo urbano local

\footnotetext{
17 Véase A. E. Araujo, "El régimen urbanístico de la propiedad privada y la determinación del ordenamiento aplicable a las áreas educacionales", Revista de Derecho Público, № 31, Caracas 1987, pp. 38-48.

${ }^{18}$ Conforme al art. 34 de la LOOU.
} 
(aprobados por Ordenanza) y en las Zonificaciones (también aprobadas por Ordenanza), en las cuales se deben establecer las variables urbanas fundamentales (arts. 86 y 87 de la Ley Orgánica) que son en concreto las que delimitan el contenido de la propiedad privada.

Por supuesto, queda a salvo de esta apreciación "La ocupación del territorio fuera de las áreas urbanas con densidades superiores a cinco (5) habitantes por hectárea", las cuales deben ser objeto de regulación urbanística, como lo indica el Parágrafo Único del artículo 51 de la Ley, de conformidad con las normas que establezca el Ministerio del Ambiente y de los Recursos Naturales Renovables y el Reglamento de la Ley, dada la incidencia general de ello en la política de ordenación del territorio.

\section{C) Las variables urbanas fundamentales y las zonificaciones}

El plan de desarrollo urbano local en sí mismo, o por instrumentos jurídicos (ordenanza) separados, debe desarrollarse mediante el establecimiento de una zonificación, es decir, de la definición de varios conjuntos (zonas) de variables urbanas fundamentales, cónsonos con los usos del suelo urbano prescritos, y que deben asignarse al área urbana que comprenda el plan, a los efectos de la ejecución de los desarrollos urbanísticos correspondientes, sea mediante urbanizaciones o edificaciones.

Es precisamente conforme a la zonificación definida y asignada al suelo urbano, que pueden realizarse urbanizaciones o edificaciones, que respondan a las variables urbanas fundamentales contenidas en ellas. Estas zonificaciones, al igual que el plan de desarrollo urbano local, deben establecerse mediante Ordenanzas (art. 80).

La noción de "variables urbanas fundamentales" es por tanto clave en el contexto de la Ley Orgánica, pues es la condición esencial para que puedan ejecutarse desarrollos urbanísticos mediante la urbanización o la edificación.

Las mismas constituyen el elemento delimitador del contenido de la propiedad urbana (art. 53), pues es conforme a ellas, que pueden usarse urbanísticamente. Ellas, por tanto, delimitan el contenido de la propiedad urbana.

Estas variables urbanas fundamentales, como se dijo, deben estar establecidas en los planes de desarrollo urbano local (art. 34) o en sus instrumentos de aplicación: las ordenanzas de zonificación. Sin embargo, cuando éstos no existan, el respectivo Concejo Municipal las debe determinar respecto al inmueble en cuestión, a solicitud de los particulares, quienes pueden presentar proyectos de urbanizaciones y edificaciones para su asignación por el respectivo Concejo Municipal, previa aprobación del Ministerio con competencia en materia de desarrollo urbano.

Ahora bien, estas variables urbanas fundamentales, definidas en el plan local y en las ordenanzas de zonificación, en el caso de las urbanizaciones, son las siguientes: 
1. El uso correspondiente.

2. El espacio requerido para la trama vial arterial y colectora.

3. La incorporación a la trama vial arterial y colectora.

4. Las restricciones por seguridad o por protección ambiental.

5. La densidad bruta de la población prevista en el plan.

6. La dotación, localización y accesibilidad de los equipamientos de acuerdo con las respectivas normas.

7. Las restricciones volumétricas.

En el caso de las edificaciones, las variables urbanas fundamentales, definidas en el plan local y en las ordenanzas de zonificación, son las siguientes:

1. El uso previsto en la zonificación.

2. El retiro de frente y el acceso según lo previsto en el plan para las vías que colindan con el terreno.

3. La densidad bruta de población prevista en la zonificación.

4. El porcentaje de ubicación y el porcentaje de construcción previstos en la zonificación.

5. Los retiros laterales y de fondo previstos en la zonificación.

6. La altura prevista en la zonificación.

7. Las restricciones por seguridad o por protección ambiental.

8. Cualesquiera otras variables que los planes respectivos impongan a un determinado lote de terreno.

Por supuesto, tanto los planes de desarrollo local que, como se dijo, deben aprobarse mediante Ordenanza, como las zonificaciones que también deben aprobarse mediante Ordenanza, son de obligatorio cumplimiento tanto para los órganos públicos como para los particulares (art. 20). En particular, estos planes y la zonificación consecuencial, son los que "delimitan el contenido del derecho de propiedad, quedando éste vinculado al destino fijado por dichos planes" (art. 53), a los efectos de cualquier desarrollo urbanístico, sea mediante urbanizaciones 0 edificaciones.

\section{D) La urbanización y la edificación}

Conforme a las antes mencionadas variables urbanas fundamentales, el régimen de ejecución del desarrollo urbano en inmuebles de propiedad privada que establece la Ley Orgánica se refiere, básicamente, a dos formas de ejecución: la urbanización y la edificación, las cuales conforme al artículo 77 de la ley:

\footnotetext{
"se regirá por las disposiciones de esta Ley y su reglamento; por lo dispuesto en leyes especiales en materias distintas a los permisos o autorizaciones administrativas; por las normas o procedimientos técnicos que dicte el Ejecutivo Nacional y; por las disposiciones de las ordenanzas municipales".
}

Con esto, por ejemplo, se eliminó la necesidad del denominado permiso sanitario de construcción que debía otorgar el Ministerio con competencia en 
materia de sanidad, y en estas materias se atribuyen a los entes nacionales y municipales, solo las competencias de inspección.

De acuerdo al artículo 78 de la Ley Orgánica, las normas y procedimientos técnicos para la ejecución de urbanizaciones y edificaciones, deben ser establecidos mediante Resolución del Ministerio con competencia en materia de desarrollo urbano en las materias técnicas de su exclusiva competencia y, en las demás materias técnicas, mediante Resolución conjunta de dicho Ministerio y de los otros Ministerios que, directamente o a través de sus organismos adscritos, tengan atribuciones urbanísticas, como las relativas a materias sanitarias y del ambiente. Estas normas y procedimientos técnicos deben ser publicadas en la Gaceta Oficial.

Tanto la urbanización como la edificación de inmuebles, debe realizarse conforme a las previsiones de los planes de ordenación urbanística y de desarrollo urbano local, y conforme con las previsiones de las Ordenanzas de Zonificación, en las cuales deben especificarse las variables urbanas fundamentales para ambas formas de ejecución (arts. 86 y 87).

Ahora bien, cuando no existan planes de ordenación urbanística, ni de desarrollo urbano local, ni ordenanza de zonificación, el artículo 125 de la Ley Orgánica establece que los particulares debían solicitar del respectivo Concejo Municipal las variables urbanas fundamentales aplicables al terreno en cuestión y pueden presentar proyectos de urbanizaciones y edificaciones para la asignación de variables por parte de dicho Concejo. Sin embargo, las mencionadas variables deben ser asignadas previa aprobación del Ministerio con competencia en materia de desarrollo urbano.

Ahora bien, cuando existan planes de ordenación urbanística y no existan planes de desarrollo urbano local u Ordenanza de zonificación, las variables urbanas fundamentales que fije el respectivo Concejo Municipal deben sujetarse a lo establecido en los planes de ordenación urbanística, de lo cual se debe informar al Ministerio del Desarrollo Urbano dentro de los quince (15) días siguientes a la asignación de dichas variables (art. 125).

\section{E) Los proyectos y la responsabilidad de los profesionales}

De acuerdo al artículo 80 de la Ley Orgánica, la realización de urbanizaciones y edificaciones requiere necesariamente de la existencia de un proyecto, que debe ser elaborado por los profesionales competentes según la Ley de Ejercicio de la Ingeniería "quienes responderán por la correspondencia del proyecto con las normas y procedimientos técnicos aplicables y con las variables urbanas fundamentales y demás prescripciones establecidas en el correspondiente plan de desarrollo urbano local o en la ordenanza de zonificación".

Además, corresponde a un profesional residente el responder porque la obra se ejecute con sujeción a los planos y demás documentos y especificaciones del proyecto. Sin embargo, el respectivo órgano municipal puede eximir del cumplimiento del requisito del "profesional residente" a las edificaciones de vivienda 
unifamiliar de una planta construida por su propietario para su habitación (art. 80). Esta parece, en todo caso, una excepción arbitraria, pues no se aplicaría a la misma vivienda, si es de dos plantas, lo cual no tiene sentido.

Con esta norma del artículo 80 de la Ley, se buscaba, hasta cierto punto, invertir la responsabilidad fáctica para la ejecución de desarrollos urbanísticos, que con anterioridad se había situado en los órganos municipales que otorgaban los permisos de construcción. Conforme a ese sistema, los particulares elaboraban sus proyectos, y el órgano municipal los revisaba hasta otorgar el Permiso de Construcción, estimándose que con éste se declaraba el derecho de uso de la propiedad urbana, quedando la responsabilidad del contenido del mismo, casi íntegramente en cabeza de los funcionarios que otorgaban el Permiso.

La Ley Orgánica de 1988 buscó trasladar y consolidar esta responsabilidad en cabeza del propietario y de los profesionales que elaboran el proyecto, como había comenzado a hacerlo la Ley Orgánica para la Ordenación del Territorio ${ }^{19}$.

\section{F) El control administrativo del desarrollo urbanístico}

La Ley Orgánica, aun cuando en su elaboración pretendió eliminar la "permisería", y en particular, la figura del Permiso de Construcción, como figura autorizatoria para el control del desarrollo urbanístico, sin embargo, no logró el objetivo proyectado, pues aun con otro nombre y otros trámites, continuó el sistema autorizatorio previo, declarativo de los derechos de uso, regulando además sistemas de controles concomitantes y posteriores a los desarrollos urbanísticos, aun cuando más simplificados.

La Ley Orgánica estableció, en efecto, una fase de control administrativo de los desarrollos urbanísticos, previa a la realización de los mismos, que puede consistir en la formulación de "consultas previas", que pueden formular los propietarios, o en la solicitud de "constancias" que deben otorgar las autoridades municipales de que la urbanización o edificación se ajusta a las variables urbanas fundamentales, las cuales, en su aplicación, se traducen en nuevas técnicas autorizatorias.

\section{a. Las consultas preliminares}

En efecto, conforme lo prevé el artículo 81 de la Ley Orgánica, toda persona interesada en construir una edificación o una urbanización, es decir, el propietario, puede hacer una consulta preliminar, por escrito, al organismo competente del Municipio, en la cual se deben solicitar las variables urbanas fundamentales; y

\footnotetext{
${ }^{19}$ Allan R. Brewer-Carías, "El régimen del urbanismo en la Ley Orgánica de Ordenación del Territorio", loc. cit., p. 98.
} 
adicionalmente, para las urbanizaciones, las condiciones generales de urbanización o parcelamiento y el nivel de dotación de las obras de servicios público.

El interesado además, debe acompañar a la consulta una copia de los documentos de propiedad del terreno; y un croquis del mismo, cuando se trate de una parcela para vivienda unifamiliar, o un levantamiento topográfico, cuando se trate de una parcela multifamiliar o para desarrollo de urbanizaciones.

Como se ha dicho, cuando no exista plan de desarrollo urbano local u ordenanza de zonificación se debe solicitar la asignación de las variables urbanas fundamentales por la autoridad municipal, conforme a lo previsto en el artículo 125 de la Ley.

La solicitud de esta consulta preliminar, como lo indica el artículo 81 de la Ley Orgánica, no es obligatoria, por lo que los propietarios pueden proceder a elaborar sus proyectos, sin formularla, y proceder a requerir la "constancia" de que los mismos se ajustan a las variables urbanas fundamentales, conforme se indica más adelante.

Sin embargo, si se formula la consulta preliminar, el respectivo funcionario municipal competente está obligado a contestarla. Dicha respuesta, si la consulta se refiere a edificaciones, debe formularla dentro de un lapso de quince (15) días hábiles siguientes contados a partir de la fecha de la recepción de la misma; y si se refiere a urbanizaciones, dentro de un plazo máximo de sesenta (60) días hábiles (art. 82), también contados a partir de la recepción de la consulta.

Como resultado de este procedimiento, la respuesta a la consulta preliminar se configura como un acto administrativo declarativo del derecho de uso urbanístico de la propiedad, el cual una vez firme no puede ser revocado por la autoridad administrativa, salvo que esté viciado de nulidad absoluta conforme al artículo 19 de la Ley Orgánica de Procedimientos Administrativos, considerándose sólo nulos ex lege los previstos en los artículos 69 y 113 de la Ley Orgánica.

La Ley Orgánica, sin embargo, nada establece para los casos en los cuales solicitada una consulta preliminar, la autoridad municipal no dé la respuesta que está obligada a dar, en los lapsos prescritos; es decir, la Ley Orgánica nada establece para proteger a los interesados frente al silencio administrativo, por lo que los remedios legales deben buscarse en otras normas. Por supuesto, en estos casos, no tiene sentido alguno aplicar la presunción del silencio administrativo negativo previsto en la Ley Orgánica de Procedimientos Administrativos (art. 4). El interesado nada ganaría ni obtendría con que se interprete que la ausencia de respuesta a su consulta preliminar se presuma como una negación o acto administrativo tácito denegatorio, ya que al formular la consulta preliminar, el interesado no está solicitando nada que pueda ser "negado". Lo que el interesado requiere de la administración municipal, en estos casos, se traduce en una conducta que sólo puede ser positiva, es decir, que se le informe sobre las variables urbanas fundamentales que rigen el uso urbanístico de su propiedad. Por ello, la abstención o negativa de la administración municipal en contestar la consulta, no puede ser remediada con la presunción derivada del silencio administrativo negativo, sino que tiene que ser remediada por la vía del recurso contencioso-administrativo contra las 
conductas omisivas de la administración municipal, previsto en la Ley Orgánica del Tribunal Supremo de Justicia.

En el caso analizado, es evidente que los funcionarios municipales competentes están obligados a responder las consultas preliminares, en lapsos legalmente determinados, razón por la cual contra la negativa o abstención en responder, procede el ejercicio del recurso contencioso-administrativo contra dichas conductas omisivas, para que el Juez obligue a la Administración a responder la consulta.

\section{b. Las constancias de conformidad con las variables urbanas fundamentales}

El control previo que se ejerce mediante la formulación de consultas preliminares y la respuesta a las mismas, como se señaló, resulta del ejercicio potestativo, pues el propietario no está obligado a formularlas. Es decir, la posibilidad de formular la consulta preliminar es un derecho del propietario, de ejercicio potestativo, no obligatorio.

Distinta es la situación, en cambio, en el caso del control previo de la ejecución del urbanismo a través del mecanismo de las "constancias de conformidad con las variables urbanas fundamentales", las cuales necesaria y obligatoriamente deben solicitarse por los propietarios antes de realizar actividades en el caso de urbanizaciones o al iniciar las obras de edificación.

Es decir, las "constancias" deben obtenerse necesariamente en ambos supuestos, con la sola diferencia de que cuando se trate de urbanizaciones, en ningún caso se puede iniciar la construcción de la misma si no se la ha obtenido previamente (art. 84); en cambio, en el caso de las edificaciones, las obras pueden iniciarse aun sin que se haya obtenido la constancia, por supuesto, a riesgo del propietario.

Sin embargo, en ambos supuestos, para la protocolización del documento de parcelamiento conforme a la Ley de Venta de Parcelas, en los casos de urbanizaciones, y la protocolización de los documentos de condominio conforme a la Ley de Propiedad Horizontal, en los casos de edificaciones, deben acompañarse las correspondientes "constancias" que habrán de agregarse a los cuadernos de comprobantes (arts. 96 y 97 ).

\section{G) El procedimiento para la obtención de la constancia}

\section{a. La notificación previa de la intención de construir (solicitud de constancia de ajuste a las variables urbanas fundamentales)}

En efecto, antes del inicio de la construcción de obras de urbanizaciones o de edificación, el propietario o su representante debe dirigirse por escrito al respectivo órgano municipal competente a fin de notificarle su intención de comenzar las obras. 
A estos efectos, el artículo 84 de la Ley Orgánica entiende por inicio de la construcción "cualesquiera actividades que persigan modificar el medio físico existente tales como la deforestación, movimiento de tierra, demolición, construcción y refacción".

A esta notificación debe acompañarse el proyecto correspondiente de la urbanización o la edificación, las certificaciones de la capacidad de suministro de los correspondientes servicios públicos provistos por los entes respectivos, los comprobantes de pago de impuestos municipales (sobre inmuebles urbanos) y los demás documentos que señalen las Ordenanzas (art. 84), las cuales podrían exigir, por ejemplo, los comprobantes de pago de las denominadas tasas de construcción.

En todo caso, en relación a esta notificación, la Ley Orgánica obliga al órgano municipal competente, a acusar recibo de la misma y su documentación anexa, para lo cual debe devolver al interesado, en el mismo acto, un comprobante de recepción fechado, firmado y sellado.

\section{b. Las certificaciones de capacidad de los servicios públicos}

Dentro de los documentos que deben acompañarse a la notificación previa de la intención de inicio de las obras de urbanización o edificación, deben destacarse las correspondientes certificaciones de la capacidad de suministro de los servicios públicos, que deben otorgar los entes prestadores de los mismos.

Estas certificaciones, por supuesto, deben obtenerse previamente a la solicitud de constancia de ajuste a las variables urbanas fundamentales, para lo cual la Ley Orgánica establece, en el artículo 84, plazos de otorgamiento de las certificaciones, de manera que los organismos de servicios públicos deben responder por escrito al propietario en un plazo no mayor de treinta (30) días continuos la consulta sobre la capacidad de suministro del servicio.

La Ley Orgánica, en este caso, tampoco establece remedio alguno contra la abstención o negativa del ente respectivo en contestar, por lo que la protección contra la conducta omisiva, en este caso, no puede ser otra que el recurso contencioso-administrativo contra la abstención o negativa.

Ahora bien, la respuesta a la consulta puede ser de incapacidad de prestación del servicio por el organismo respectivo, en cuyo caso, el propietario puede proponer soluciones o alternativas de suministro incluyendo la prestación privada del servicio en los términos y condiciones que señale el organismo competente. En estos casos, el organismo correspondiente debe responder por escrito sobre las alternativas propuestas en un plazo no mayor de treinta (30) días continuos. De lo contrario, si no responde, el propietario también puede acudir a la vía contencioso-administrativa contra las conductas omisivas de los entes, para que el juez los obligue a responder la consulta. 


\section{c. La respuesta a la solicitud de constancia de ajuste a las variables urbanas fundamentales}

Conforme al artículo 85 de la Ley Orgánica, los organismos municipales disponen de un plazo de treinta (30) días continuos, en el caso de edificaciones o de noventa (90) días continuos, en el caso de urbanizaciones, "para constatar únicamente que el proyecto presentado se ajusta a las variables urbanas fundamentales establecidas en esta Ley".

Como resultado de esta constatación, el organismo respectivo debe decidir si el proyecto se ajusta o no a las variables urbanas fundamentales, y ello lo debe hacer mediante un acto administrativo formal.

En primer lugar si el proyecto se ajusta a las variables urbanas fundamentales, el acto administrativo consiste en el otorgamiento de la constancia respectiva. Así, el artículo 85 de la Ley Orgánica dispone que cumplida la constatación respectiva, el organismo municipal, visto el informe del inspector asignado o contratado para la obra, debe expedir al interesado la constancia respectiva dentro del plazo antes indicado.

Una vez obtenida la constancia, dentro de los cinco (5) días siguientes a la expedición de la constancia, el interesado debe presentar a los organismos de la administración urbanística nacional que corresponda, duplicados de expediente y de la referida constancia, por lo cual éstos deben expedir al interesado un recibo de la citada copia. Esto es particularmente importante para los casos de la administración sanitaria y ambiental, y el proceso de inspección subsecuente.

Como hemos señalado, en el caso de las urbanizaciones, es sólo después que el interesado ha obtenido la constancia de que el proyecto se ajusta a las variables urbanas fundamentales, que el interesado puede iniciar la construcción de obras.

Pero en segundo lugar, la decisión que puede adoptar el respectivo ente municipal, podría ser de carácter negativo, cuando considere que el proyecto no se ajusta a las variables urbanas fundamentales. De acuerdo al artículo 88 de la Ley Orgánica, esta decisión, que también es un acto administrativo, debe ser notificada al interesado mediante oficio motivado.

En estos casos, si se trata de una urbanización, como se dijo, las obras de la misma no pueden iniciarse; y en los casos de edificaciones, si las obras se han iniciado, el acto administrativo contentivo de la decisión de que el proyecto no se ajusta a las variables urbanas fundamentales debe, además, ordenar la paralización de la obra dentro de los ocho (8) días siguientes.

En estos casos de actos administrativos que resuelvan que el proyecto no se ajusta a las variables urbanas fundamentales, el interesado puede optar por dos vías:

En primer lugar, puede allanarse al contenido del acto y presentar modificaciones al proyecto para ajustarse a las variables urbanas fundamentales 0 
formular observaciones a la decisión. En estos casos, recibido el proyecto modificado o las observaciones del interesado, el organismo municipal dispone de quince (15) días continuos para expedir la constancia o para resolver que el proyecto no se ajusta a las variables urbanas fundamentales.

En segundo lugar, en todo caso de decisión de que el proyecto no se ajustara a las variables urbanas fundamentales, conforme a lo previsto en el artículo 89 de la Ley Orgánica, el interesado puede interponer recurso de reconsideración ante el órgano municipal que hubiese dictado el acto. Dicho órgano tiene, de acuerdo a la Ley Orgánica, un plazo de treinta (30) días para decidir el recurso, y contra esta decisión puede interponerse recurso jerárquico ante el Alcalde dentro de los treinta (30) días siguientes. Posteriormente, también puede ocurrirse ante la jurisdicción contencioso-administrativa.

\section{H) La naturaleza autorizatoria de las constancias de ajuste a las variables urbanas fundamentales}

Tal como se ha señalado, estas constancias de que el proyecto presentado se ajusta a las variables urbanas fundamentales, son actos administrativos que habilitan la construcción tanto de urbanizaciones como de edificaciones. En el primer caso, constituyen la condición para el inicio de las obras de urbanización; en el segundo caso, constituyen la condición para la continuación de las obras de edificación.

El contenido de estas constancias es, sin duda, el mismo de un acto administrativo autorizatorio, pues habilitan el ejercicio de los derechos de uso de la propiedad urbana. Por ello, equivalen, con otro nombre, a los antiguos "permisos de construcción"; sin ellas, no se pueden iniciar las obras de urbanización; y sin ellas no se puede continuar con la mínima seguridad jurídica, las obras de edificación. En todo caso, como actos administrativos declarativos de derechos, las constancias, una vez firmes, no pueden ser revocadas por la autoridad administrativa, salvo que estén viciadas de nulidad absoluta conforme al artículo 19 de la Ley Orgánica de Procedimientos Administrativos, considerándose sólo como nulidad absoluta ex lege (ord. 1, art. 19 LOPA), la prevista en los artículos 69 y 113 de la Ley Orgánica.

\subsection{La fallida intención de derogar y sustituir el régimen legal establecido en las Leyes Orgánicas de 1983 y 1988}

Ahora bien, como se dijo, en septiembre de 2005 tanto la Ley Orgánica para la Ordenación del Territorio de 1983 como la Ley Orgánica de Ordenación Urbanística de 1988 fueron derogadas por la Ley Orgánica para la Planificación y Gestión de la Ordenación del Territorio (LOPGOT) ${ }^{20}$, la cual sin embargo, sucesivamente tuvo su

${ }^{20}$ Publicada inicialmente en Gaceta Oficial № 38.263 de fecha 1 de septiembre de 2005, fue luego reimpresa por error material (omisión de los artículos 60 y 61) en la Gaceta Oficial № 38.264 del 2 
vigencia en suspenso, hasta que en febrero de 2007 fue derogada sin que jamás hubiera entrado en vigencia.

La Ley que nunca fue tal, pretendía refundir los textos de las dos Leyes Orgánicas precedentes sobre ordenación del territorio y ordenación urbanística, con muy pocos cambios significativos. Entre ellos, sin embargo, en materia de control de la ejecución de actividades que implicasen ocupación del suelo urbano, se pretendía volver al antiguo sistema de las autorizaciones municipales (permisos de construcción) que la Ley Orgánica de Ordenación Urbanística de 1987 había buscado erradicar.

A pesar de que esta Ley Orgánica nunca entró en vigencia, estuvo publicada en gaceta oficial durante casi dos años, por lo que consideramos de interés comentar su contenido específicamente en cuanto a las limitaciones a la propiedad privada que pretendía establecer por razón de ordenación del territorio y de la ordenación urbanística.

\section{LAS proyectadas LIMITACIONES AI uso de la propiedad territorial COMO CONSECUENCIA DE LA ORDENACIÓN DEL TERRITORIO en la Ley Orgánica de 2005 que nunca entro en vigencia}

\subsection{Régimen general de la vinculación de la propiedad a los planes de ordenación y las "constancias de uso conforme" como mecanismo de control \\ El artículo 122 de la Ley Orgánica estableció expresamente que

\begin{abstract}
"los planes de ordenación urbanística, los planes municipales de ordenación del territorio y planes especiales afectan el contenido del derecho de propiedad, quedando éste derecho vinculado al destino fijado por dichos planes, conforme al ordenamiento constitucional, las disposiciones contempladas en la ley y demás normas aplicables a la materia".
\end{abstract}

En este aspecto, la Ley Orgánica no variaba mayormente lo previsto en las Leyes Orgánicas que pretendía derogar. En cambio, donde realmente si buscaba establecer un cambio radical era en materia de control administrativo del uso de la propiedad inmueble, al pretender sustituir el régimen general de las aprobaciones y autorizaciones que establecía la Ley Orgánica para la Ordenación del Territorio de 1983, disponiendo en cambio sólo que las actividades que tuvieran incidencia espacial e impliquen acciones de ocupación del territorio debían estar ajustadas a los planes de ordenación del territorio (art. 27). En realidad, sólo en materia urbanística es que se regulaban las autorizaciones (art. 136)

En consecuencia, para asegurar que la sujeción de actividades se ajustase a los planes, la Ley Orgánica de 2007 pretendió establecer como mecanismo de control de la ejecución de los planes, la necesidad de que tanto los entes públicos

de septiembre de 2005; y luego, de nuevo, en la Gaceta Oficial № 38.279 del 23 de septiembre de 2005. 
como los particulares, antes de realizar dichas actividades, obtuvieran de la autoridad competente para el control de los planes, una "constancia de uso conforme", las cuales de acuerdo con el artículo 27 de la Ley Orgánica, debían ser otorgadas o negadas por las autoridades encargadas del control de la ejecución de los planes dentro de sus respectivas competencias.

Así , en el ámbito urbanístico municipal, lo que se pretendía regular aún cuando en forma imperfecta, eran las constancias de ajuste a las variables urbanas fundamentales (art. 145) que antes se han comentado.

Por otra parte, se debe destacar que conforme al artículo 116 de la Ley Orgánica que nunca entró en vigencia, la constancia de uso conforme con los planes debía "ser solicitada aun cuando no se hayan aprobados los correspondientes planes de ordenación del territorio". Por tanto, aún ante la inexistencia de planes, todas las actividades que hubieran tenido incidencia espacial e implicasen ocupación del territorio debían tener la constancia de uso conforme otorgada por la autoridad de control correspondiente. Asimismo, en estos casos, dicha constancia se hubiera debido otorgar tomando en cuenta los siguientes criterios:

1. Las directrices de ordenación del territorio establecidas en los Planes existentes que sean aplicables.

2. La posibilidad de atender con servicios públicos la demanda a generarse por la actividad propuesta.

3. El impacto ambiental de la actividad propuesta.

4. La vocación natural de las zonas y, en especial, la capacidad y condiciones específicas del suelo.

5. Las regulaciones ya existentes para el uso de la tierra.

6. Las limitaciones geográficas, especialmente las que vienen impuestas por la anegabilidad de los terrenos y por las condiciones propias de las planicies inundables, y la fragilidad ecológica por su vulnerabilidad y riesgo ante la ocurrencia de fenómenos naturales y tecnológicos.

7. Los usos existentes en el área, siempre que no sean contrarios a lo establecido en las normas ambientales urbanas y de calidad ambiental.

8. Los demás factores que se consideren relevantes a los mencionados usos.

La constancia de uso conforme, en todo caso, no era una autorización administrativa; era sólo un acto administrativo emanado de la autoridad competente declarativo de certeza en relación a la conformidad de un uso propuesto al plan. Por ello es que el artículo 29 de la Ley Orgánica consideraba como "nula y sin ningún efecto la constancia de uso conforme otorgada en contravención a los planes de ordenación del territorio y aquéllas otorgadas por autoridades no competentes según esta Ley".

En efecto, como lo indicaba expresamente el artículo 28 de la Ley Orgánica, la constancia de uso conforme, sólo: 
territorio mediante la ejecución de las obras, programas, proyectos o la afectación de recursos naturales."

Las actividades respectivas, en todo caso, debían ajustarse a las directrices y lineamientos establecidos en el plan nacional vigente.

Conforme al artículo 30 de la Ley Orgánica, la decisión correspondiente al otorgamiento o no de las constancias, debía adoptarse en un lapso de sesenta (60) días continuos, contados a partir de la recepción de la solicitud respectiva. Agregaba el artículo 30 de la Ley Orgánica que "vencido dicho lapso sin que hubiere habido respuesta se considerará otorgada, a cuyo efecto, las autoridades respectivas están obligadas a otorgar la respectiva certificación".

Es decir, la Ley Orgánica pretendía regular expresamente el llamado silencio administrativo positivo, de manera que la falta oportuna de respuesta, implicaba automáticamente el otorgamiento de la constancia, es decir, la declaración de las autoridades encargadas del control de la ejecución de los planes, de que la actividad o uso del suelo propuesta se ajustaba al plan.

Debe señalarse, por último, que conforme al artículo 173 de la Ley Orgánica, las constancias de uso conforme o cualquier otro tipo de acto administrativo contrario a las disposiciones de la Ley y a los planes de ordenación del territorio, se consideraban nulos, no pudiendo generar derechos a favor de sus destinatarios; y los funcionarios públicos que los otorgasen incurrirían en responsabilidades disciplinarias, administrativas, penales o civiles según el caso.

\section{LAS proyectadas LIMITACIONES Al uso de la propiedad territorial COMO CONSECUENCIA DE LA ORDENACIÓN urbanistica conforme a la Ley orgáníca que nunca entró en vigencia}

\subsection{Las limitaciones a la propiedad privada y la vinculatoriedad de los planes}

En materia de limitaciones a la propiedad territorial por razones de ordenación urbanística, la Ley Orgánica para la Planificación y Gestión de la Ordenación del Territorio de 2005, que nunca entró en vigencia, siguió la misma orientación del artículo 66 de la Ley Orgánica de Ordenación del Territorio de 1983, y del artículo 52 de la Ley Orgánica de Ordenación Urbanística de 1988, leyes que que buscaba derogar; y a tal efecto, en su artículo 121 estableció que "la propiedad urbana tiene una función social", haciendo referencia al artículo 115 de la Constitución de 1999, que por lo demás, sólo sujeta la propiedad a las restricciones establecidas en las leyes.

Siguiendo la misma orientación del artículo 66 de la Ley Orgánica de Ordenación del Territorio de 1983, y el artículo 53 de la Ley Orgánica de Ordenación Urbanística de 1987, el artículo 118 de la Ley Orgánica que nunca entró en vigencia, también disponía que los Planes de Ordenación Urbanísticos "delimitan el contenido del derecho de propiedad, quedando este derecho vinculado al destino 
fijado por los planes, conforme al ordenamiento constitucional y legal"; norma que se repetía en el artículo 122 de la misma Ley Orgánica.

Por supuesto, la consecuencia de ello es que las actuaciones que se realizasen en suelo urbano con fines urbanísticos, debían requerir la previa adopción de un plan. Tal como lo precisó el artículo 101 de la Ley Orgánica: "las actuaciones en el suelo con fines urbanísticos requieren la previa aprobación de los respectivos planes de ordenación del territorio urbanísticos, para la asignación de uso y de su régimen correspondiente, así como de la fijación de volúmenes, densidades y demás procedimientos técnicos".

Por tanto, necesariamente, para que hubieran podido realizarse actividades privadas en áreas urbanas, tenía que haber habido un plan de desarrollo urbano conforme a lo que se estableciera en la Ordenanza que definiera el uso y el régimen correspondiente a ese uso, así como la fijación de volúmenes, densidades y demás procedimientos técnicos. Por tanto, de acuerdo a esta norma, la propiedad y su uso quedaban vinculada al plan, por lo que sin plan no había posibilidad de uso, y no se hubiera podido autorizar su desarrollo.

Por otra parte, el artículo 123 de la Ley Orgánica que nunca entró en vigencia, también establecía sobre el carácter de las limitaciones legales a la propiedad por razones de urbanismo que:

\footnotetext{
Las contribuciones, restricciones y obligaciones establecidas en leyes, reglamentos, planes y ordenanzas urbanísticas se consideran limitaciones legales del derecho de propiedad, y en consecuencia no confieren, por sí solas, derecho a indemnización. Ésta sólo podrá ser acordada en los casos de limitaciones que comporten vinculaciones singulares y que establezca la ley. En estos casos, a los efectos de determinar la indemnización se seguirán los criterios establecidos en la presente Ley y demás leyes que rigen la materia.
}

\subsection{El régimen de la ejecución del desarrollo urbanística, el ajuste las variables urbanas fundamentales y las autorizaciones municipales}

En materia de ejecución del urbanismo, la Ley Orgánica que nunca entró en vigencia, disponía que toda actividad que implicase ocupación del territorio a ser desarrolladas en áreas urbanas, a ser ejecutadas por organismos públicos y privados o por particulares, debía estar acorde con las Ordenanzas Municipales, en particular las que estableciera el plan de desarrollo urbano local y debía además; estar ajustadas a las Variables Urbanas Fundamentales previstas en Ley Orgánica, así como a los demás instrumentos jurídicos que regulasen la materia urbanística, "siendo el ente competente para su autorización el municipio"(art. 136).

Las Variables Urbanas, se definían en la Ley Orgánica que nunca entró en vigencia como los factores condicionantes del desarrollo urbanístico, los cuales debían tener relación con el espacio, la topografía, condiciones geológicas, densidad de la población, la dotación de los servicios básicos y las restricciones volumétricas (art. 4), enumerándose en los artículos 147 y 148, con el mismo 
contenido que el establecido en la Ley Orgánica de 1987 para urbanizaciones y edificaciones. Solo en materia de variables ambientales la Ley Orgánica que nunca entró en vigencia las explicitaba más detalladamente (arts. 153 y 154).

Como se ha dicho Ley Orgánica 1987, eliminó los antiguos permisos de construcción, y los sustituyó por el otorgamiento de las constancias de ajuste a las variables urbanas fundamentales, que constituyen actos administrativos consistentes en dejar constancia de que el proyecto presentado de uso del suelo urbano se ajusta a las variables urbanas fundamentales, y habilitan la construcción tanto de urbanizaciones como de edificaciones. En el primer caso, constituyen la condición para el inicio de las obras de urbanización; en el segundo caso, constituyen la condición para la continuación de las obras de edificación.

El contenido de estas constancias, como se ha dicho, es el mismo de un acto administrativo autorizatorio, en el sentido de que sin ellas no se puede iniciar las obras de urbanización; y sin ellas no se puede continuar con la mínima seguridad jurídica, las obras de edificación.

En contraste, la Ley Orgánica que nunca entró en vigor, no buscó regular específicamente la necesidad de la obtención de las constancias de ajuste a las variables urbanas fundamentales, pero por la mención que de ellas se hacía en el artículo 145, y por la regulación general de las "constancias de uso conforme" respecto de todos los planes de ordenación del territorio (que comprende a los de ordenación urbanística), podría interpretarse que los interesados en desarrollar urbanísticamente un inmueble para urbanización o edificación, debían haber podido solicitar de la autoridad municipal (en forma potestativa, no obligatoria como se regula en la Ley de 1987), que se le expidiera una constancia de uso conforme, lo que hubiera equivalido en materia urbanística, a la constancia de variables urbanas fundamentales.

Pero dicha constancia, conforme a la orientación de la Ley nunca vigente (art. 28), no tenía sino un valor declarativo, pues se disponía que no otorgaban derecho para la ocupación del territorio mediante la ejecución de obras. En consecuencia, los interesados, para urbanizar o para edificar, lo que hubieran tenido que haber solicitado habría sido una autorización de la autoridad municipal tal como se mencionaba en general en el artículo 136. Puede decirse, así, que hasta cierto punto la Ley Orgánica que nunca entró en vigencia, buscaba "revivir" los antiguos permisos municipales de construcción.

El artículo 145 de la Ley Orgánica que nunca entró en vigencia, sin embargo, autorizaba la realización en forma paralela del urbanismo y las edificaciones, "siempre y cuando en las constancias de ajuste de variables urbanas fundamentales, tanto de urbanizaciones como de edificaciones, se establezcan las etapas de ejecución con la respectiva previsión de equipamientos urbanos, dotación de servicios y vialidad correspondiente a cada una de las etapas," siendo esta la única norma de la Ley Orgánica nunca vigente, en la cual se hacía referencia a constancias de ajuste de variables urbanas fundamentales. 
Por otra parte, en los casos de ejecución paralela de desarrollos, la Ley Orgánica que nunca entró en vigencia, disponía que para efecto de la entrega al municipio de los equipamientos urbanos, dotación de servicios y la vialidad correspondiente a cada etapa, ésta debía efectuarse previa a la solicitud de "Certificación de Terminación de Obra de las Edificaciones", siendo esta la única vez en la que dicha Ley nunca vigente, se refería a esta figura de "certificación de terminación de obra de edificaciones."

\subsection{Las técnicas municipales de control que se proponían}

El artículo 149 de la Ley Orgánica nunca vigente, los organismos municipales competentes eran los llamados a inspeccionar, directamente o mediante contrato de servicios profesionales, la construcción de las urbanizaciones y edificaciones "a fin de verificar el cumplimiento de las variables urbanas fundamentales y de las normas técnicas nacionales en cuanto a urbanismo y edificación". A tal efecto, se buscaba disponer que el propietario de la obra debía contribuir a costear la fiscalización por contrato de servicio mediante el pago de una tasa de inspección, que debía fijar la Alcaldía municipal a través de la Ordenanza correspondiente

Para realizar esta labor de inspección, se proyectaba que los Municipios establecieran las dependencias y procedimientos de inspección que correspondiera a sus necesidades, recursos y demás particulares circunstancias, debiendo el personal de inspección, estar integrado por profesionales competentes según la Ley de la materia, es decir, la Ley del Ejercicio de la Ingeniería y Profesiones Afines.

La Ley nunca vigente, por otra parte, a diferencia de la Ley Orgánica de 1987, buscaba atribuir también poderes de inspección de urbanizaciones y edificaciones a las autoridades nacionales competentes, por ejemplo, la sanitaria y la ambiental conforme las respectivas leyes especiales (art. 150).

En esta materia de inspección, por otra parte, Ley Orgánica nunca vigente, pretendió eliminar disposiciones de importancia que establece la Ley Orgánica de 1987, entre ellas, la que exige que de toda inspección debe elaborarse un acta en el mismo sitio de la obra, que debe entregarse en copia al profesional residente 0 al propietario, quien debe firmar el original como constancia de haberla recibido (art. 97). La norma agrega que en caso de que en el acta se constatase la infracción de normas técnicas de arquitectura, ingeniería o urbanismo, la autoridad municipal, dentro de los 5 días siguientes al conocimiento de la infracción, debe participar por escrito al organismo competente según la materia, a los fines de la aplicación de la sanción que fuere pertinente.

La Ley nunca vigente también pretendió eliminar la norma que establecía la iniciativa popular de control prevista en el artículo 104 de la Ley Orgánica de 1987, al establecer que "toda persona, Asociación de Vecinos u organizaciones gremiales, sociales, culturales, deportivas u otras que funcionen en la comunidad, podrá requerir de los órganos administrativos de control urbanístico, nacionales o 
municipales, la adopción de las medidas pertinentes para el cumplimiento de los planes urbanos y de las normas que los complementan".

\section{APRECIACIÓN FINAL}

El caso de la sanción de la Ley Orgánica para la Planificación y Gestión de la Ordenación del Territorio, sancionada en septiembre de 2005 y derogada en febrero de 2007 y que nunca entró en vigencia, es una muestra palpable y lamentable del deterioro de la función legislativa que ejerce la Asamblea Nacional en Venezuela. Entre las causas, sin duda, desde el inicio está la eliminación del bicameralismo en la Constitución de 1999 y del control y balance que en la formación de las leyes ejercían las dos Cámaras Legislativas (Senado y Diputados) que antes funcionaban en el país. Además está la destrucción progresiva que se fue realizando en los últimos años en el seno de la Asamblea Nacional, de los instrumentos de asesoría en materia de formación de las leyes, y la ausencia más absoluta de participación de los sectores interesados en la redacción de las mismas.

Este caso, por lo demás, lo evidencia el hecho mismo de la vacatio legis prevista inicialmente, que no era otra cosa que una manifestación de inseguridad que los legisladores tenían sobre las bondades de la reforma que habían sancionado, y las tantas observaciones que se le formularon a la Ley después de publicada.

No extraña, por tanto, que sea esta incompetencia del Legislador la que lo haya llevado con tanta rapidez y facilidad, a delegar en enero de 2007, mediante Ley Habilitante, en el Ejecutivo, la legislación básica del país, pensando que quizás en la Administración Pública habría mayor capacidad técnica para la elaboración de leyes, renunciando así a la razón justificadora de su propia existencia. Quizás sea este el anticipo de su propia futura disolución en una Asamblea del Poder Popular y, con ella, de la extinción del principio de la separación de poderes. 